\title{
SYNTHESIS OF TRIPHENYLAMINE-BASED RHOMBIMINE MACROCYCLE BY [2+2] CYCLOCONDENSATION REACTION BETWEEN (1R,2R)-DIAMINOCYCLOHEXANE AND 4,4'-DIFORMYL TRIPHENYLAMINE
}

\author{
Loredana Vacareanu (Stafie), Virgil Barboiu, Daniel Timpu, Mircea Grigoras* \\ “P. Poni” Institute of Macromolecular Chemistry, 41A Gr. Ghica Voda alley, 700487-Iasi, Romania \\ *e-mail: grim@icmpp.ro, Phone: (040) 232-217454,Fax: (040)232-211299
}

\begin{abstract}
A Schiff base macrocycle with persistent rhomboidal shape was synthesized in excellent yield through $[2+2]$ condensation reaction between $(\mathrm{R}, \mathrm{R})$-1,2-diaminocyclohexane and 4,4'-diformyltriphenylamine. The dimeric macrocylic structure was proved by electrospray ionization mass spectrometry (ESI-MS), ${ }^{1} \mathrm{H}-\mathrm{NMR}$, and FTIR spectroscopy. The complexation properties were evidenced by UV absorption.
\end{abstract}

Keywords: triphenylamine group, Schiff base macrocycle, rhombimine.

\section{Introduction}

Imine macrocycles [1] derived from (R,R)-1,2-diaminocyclohexane [2-6] and aromatic dialdehydes have been extensively studied in the last years due to their exotic shapes and potential applications in supramolecular chemistry and materials science. Depending on dialdehyde geometry imine macrocycles with different persistent shapes, such as chiral trianglimines [2a,b,e,3a,b,4a-c,e,f,5a-c,6], rhombimines [2c,h,4c,f,5b,6] rectanglimines [2f] and spherands [2h] are obtained.

Arylamine-based polymers have attracted much attention due to their unique properties that allow them to have potential application in organic electronics, photonics and spintronics [7-9]. Particularly, triphenylamine-based polymers have good hole-transporting properties, high light-emitting efficiency, photoconductivity and photorefractivity, large twophoton absorption cross sections and stabilization effect of high-spin polyradicals in organic magnets. Due to the good electron-donating nature of triphenylamine (TPA), its polymers have been widely used as hole-transporting materials for a number of applications, such as xerography, organic field-effect transistors, photorefractive systems, light emitting diodes etc [10-12]. These interesting properties are associated with presence of TPA unit that contains the nitrogen center (the electroactive site) linked to three electron-rich phenyl groups in a propeller-like geometry [13]. Triphenylaminebased oligomers with dendrimer or star-shaped architectures have been synthesized for various applications as organic light emitting materials or field-effect transistors and two-photon related applications but only a cyclic TPA dimer was reported until now [14]. This compound was synthesized in very low yield (9\%) by McMurry coupling reaction from 4,4'-diformyltriphenylamine and have the two TPA units coupled at 4,4' positions by two ethylene bridges. The supramolecular structure is columnar with cyclic dimer stacked each on other that allows a high hole mobility.

The aim of this communication is to present synthesis of a Schiff base macrocycle by [2+2] cyclocondensation of 4,4'-formyl TPA with (R,R)-1,2-diaminocyclohexane and its spectral data and properties.

\section{Results and discussion}

Previously, we have studied synthesis of some Schiff base polymers by solution polycondensation of 3,6-bisformyl $\mathrm{N}$-alkyll carbazole and 4,4'-bisformyl triphenylamine with aromatic diamines [15-17]. Both dialdehyde comonomers have a bent structure with in plane-projected angle between the two Ar-CHO close by $120^{\circ}$. When diamine partner has also a bent structure, i.e. 3,6-diamino $\mathrm{N}$-alkyl carbazole, formation of macrocycles of different shapes and dimensions has been evidenced [16]. Another diamine, (R,R)-1,2-diaminocyclohexane, has a rigid and bent structure and in planeprojected angle between $\mathrm{C}-\mathrm{NH}_{2}$ functions close to $60^{\circ}$ and was much used in combination with suitable dialdehydes to obtain cyclic compounds of different forms and dimensions [2-6]. There is only a short communication about synthesis of a rhombimine based on 4,4'-bisformyl triphenylamine without a detailed study of its properties and spectral data $[2 \mathrm{~g}]$. The aim of this communication is to present our results regarding synthesis and some properties of rhombimine (프) (Scheme 1). Condensation of $\underline{\mathbf{1}}$ with $\underline{\mathbf{2}}$, in dichloromethane at room temperature or under reflux, yielded the rhombimine $\underline{3}$ in nearly quantitative yield whithout the use of dehydrating conditions and without any external template. It is noteworthy that the [2+2] macrocycle is the only cyclic compound observed by ESI-MS spectroscopy in the crude product of condensation reaction. The pure product was obtained by recrystallization from N,N-dimethylformamide as colorless powder. The structure of the compound was confirmed by ${ }^{1} \mathrm{H}-\mathrm{NMR}$, EIS-MS, FTIR, UV spectroscopy. 


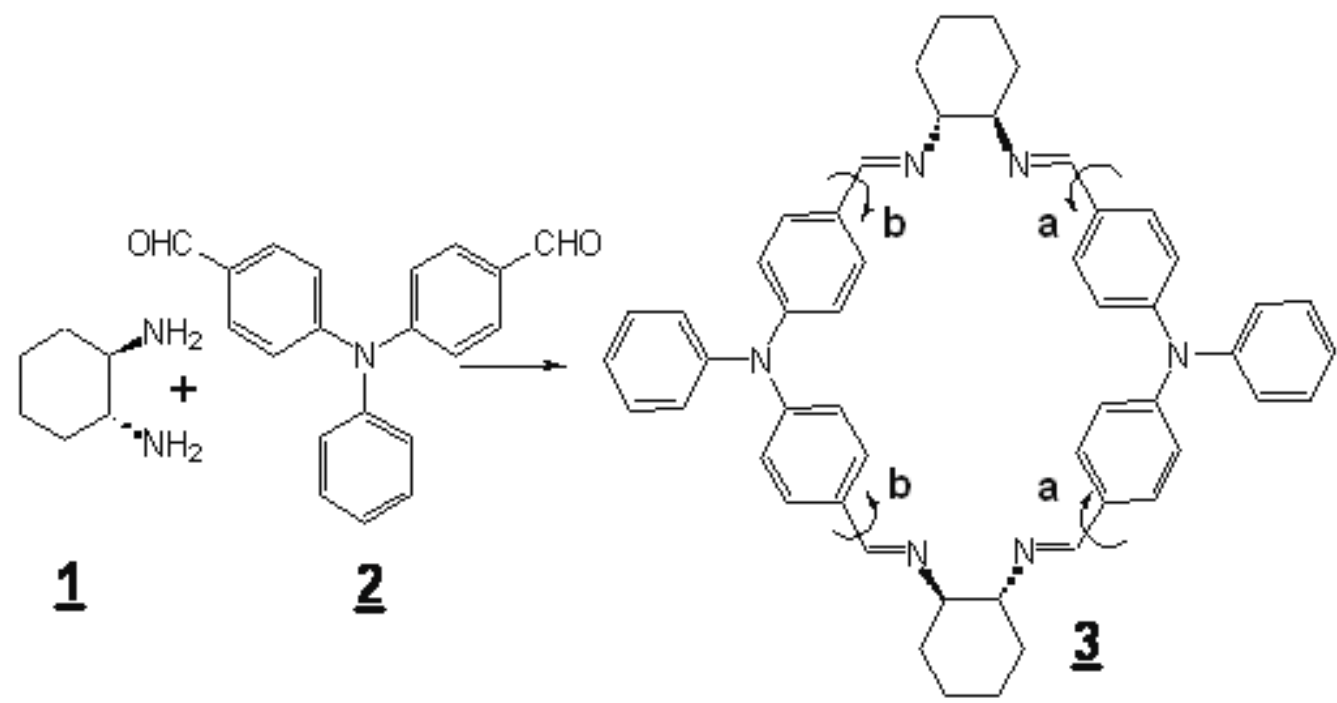

Scheme 1. Synthesis of rhombimine $\underline{3}\left(\mathrm{CH}_{2} \mathrm{Cl}_{2}\right.$, reflux, $\left.5 \mathrm{hr}\right)$.

The ${ }^{1} \mathrm{H}-\mathrm{NMR}$ spectrum of macrocycle $\underline{3}$ after recrystallization from DMF is consistent with the proposed structure in Scheme 1, showing a singlet signal at $7.91 \mathrm{ppm}$ for the four imine protons. The assignments of other signals are presented in Figure 1 and signal integrals are in good agreement with number of protons. Some signals positioned at 7.26, 2.96 and $2.88 \mathrm{ppm}$ (labeled on Figure) come from $\mathrm{CHCl}_{3}$ and $\mathrm{DMF}$ traces. There are no signals for $-\mathrm{CHO}$ or $-\mathrm{NH}_{2}$ end groups. When a $\mathrm{CDCl}_{3}$ solution of $\underline{\mathbf{3}}$ was left several days at room temperature its proton NMR spectrum showed significant modifications (Figure 2). So, new signals appeared for imine (8.11-8.13 ppm), aromatic (7.42-7.44 ppm) and $-\mathrm{CH}-\mathrm{N}=$ diamine $(3.35 \mathrm{ppm})$ protons. The intensities of the new signals integrals are correlated between them. We assume this behavior to an anti-syn isomerization process that takes place in solution by a ring inversion induced by a concerted rotation around two (a case) or four (a and $\mathbf{b}$ ) imine bonds. So, by dissolution $\underline{\mathbf{3}}$ in DMF and heating then at reflux temperature, a colorless fine powder in anti form resulted. It was observed that the conformer anti spontaneously isomerizes to syn-anti or all syn isomers with one or both $\mathrm{N}-\mathrm{Ph}$ moieties in syn arrangement if it is immediately cooled in chloroform (Figure 3).

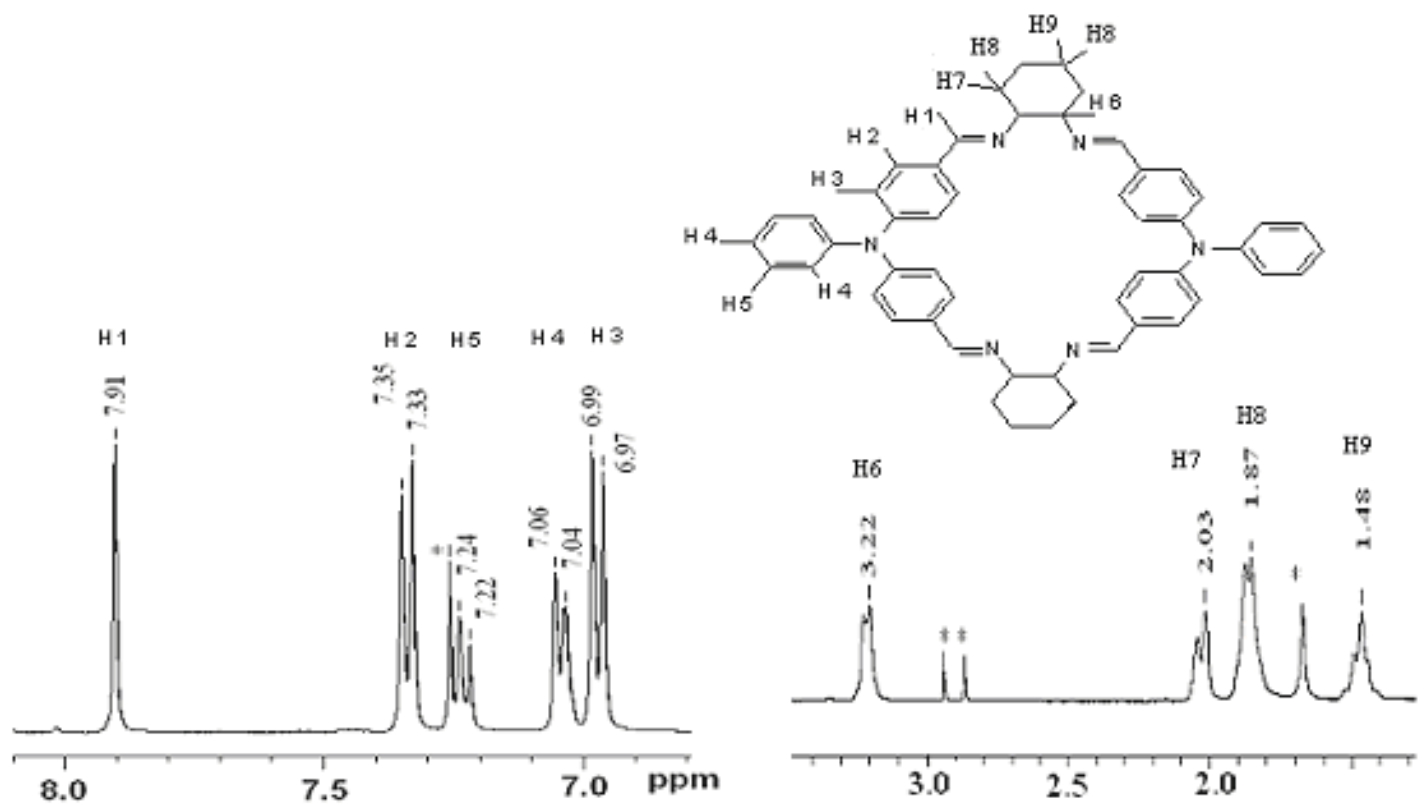

Figure 1. ${ }^{1} \mathrm{H}-\mathrm{NMR}\left(\mathrm{CDCl}_{3}\right)$ spectrum of $\underline{3}$ after recrystallization from $\mathrm{N}, \mathrm{N}$-dimethylformamide. 
The isomerization is not completely and a mixture of three isomers results. The crude product obtained from synthesis shows a NMR spectrum rather similar with that presented in Figure 2 . Another imine macrocyle based on $\underline{\mathbf{1}}$ and 3,6-bisformyl N-ethyl carbazole displayed the same temperature dependence of the NMR spectrum [4c].

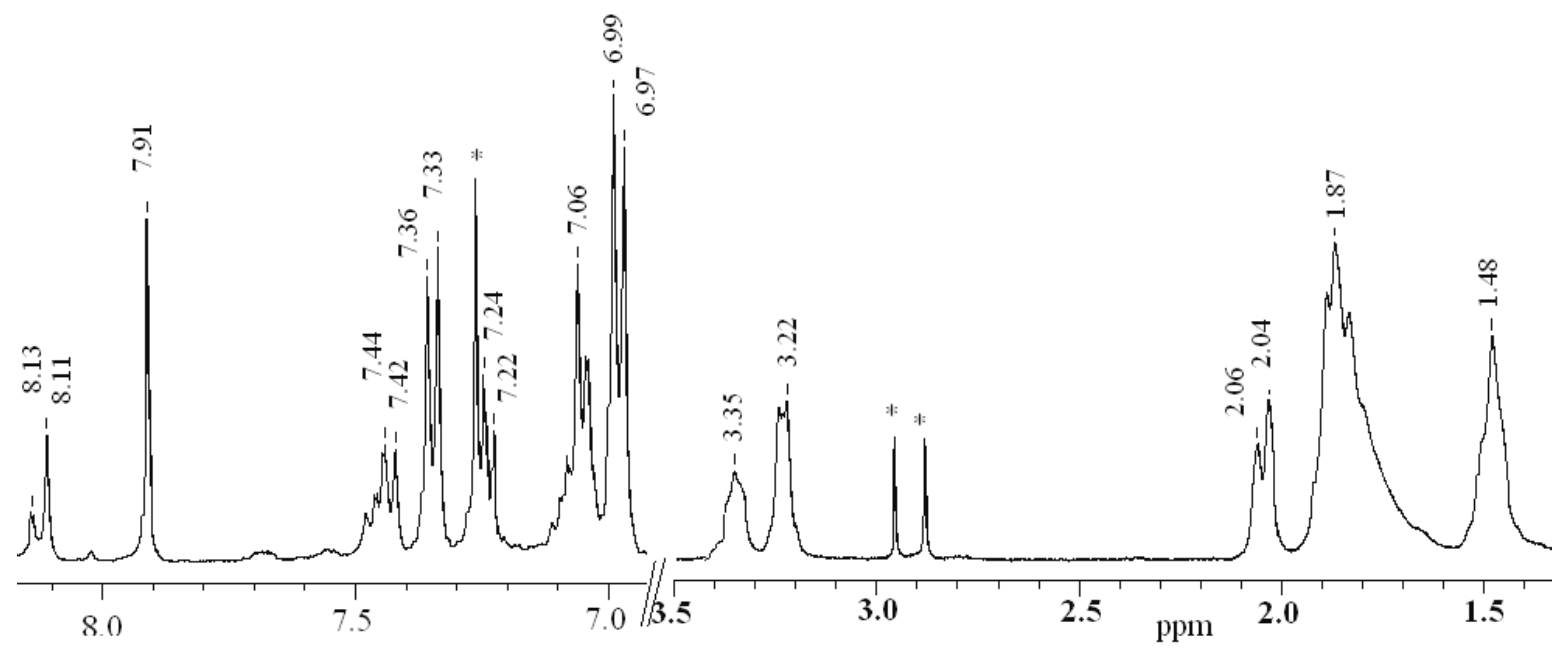

Figure 2. ${ }^{1} \mathrm{H}-\mathrm{NMR}$ spectrum $\left(\mathrm{CDCl}_{3}\right)$ of $\underline{3}$ (presented in Figure 1) registered again but after several days.

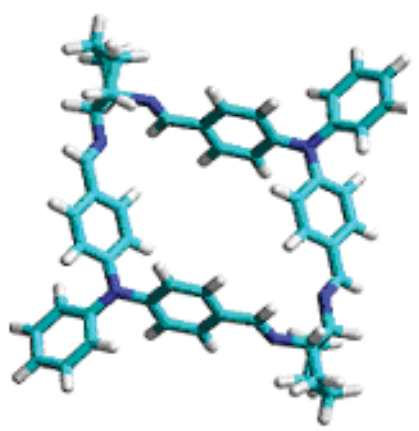

a

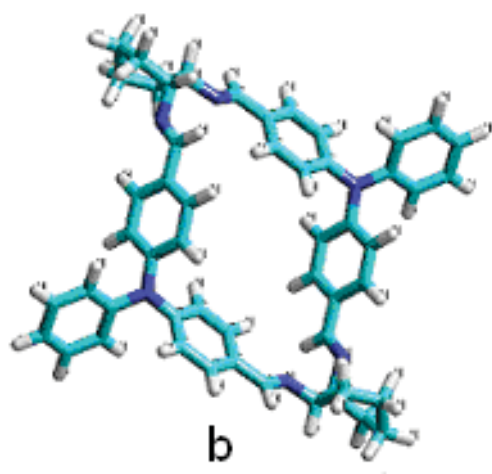

b

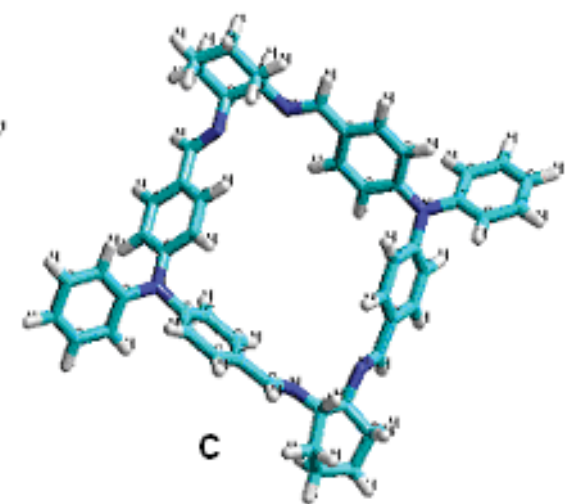

Figure 3. Models illustrating a) all-anti isomer, b) all-syn isomer and c) syn-anti isomer.

Having in mind the reversibility of imine condensation reaction, the first thing done was to check if an expansion of macrocycle is responsible for NMR spectrum changes. The ESI-MS spectra of $\underline{\mathbf{3}}$ recorded after recrystallization and after preserving in chloroform solution for several days were identically, with the molecular ion peak at $759.3 \mathrm{Da}$ and fragmentation ions peak $380.15 \mathrm{Da}$, what is consistent with the structure proposed in Scheme 1. Therefore, the modifications observed by NMR spectroscopy could be assigned only to an isomerization process and if the sample is protected against moisture or acid traces the isomerization is not accompanied by hydrolysis. 


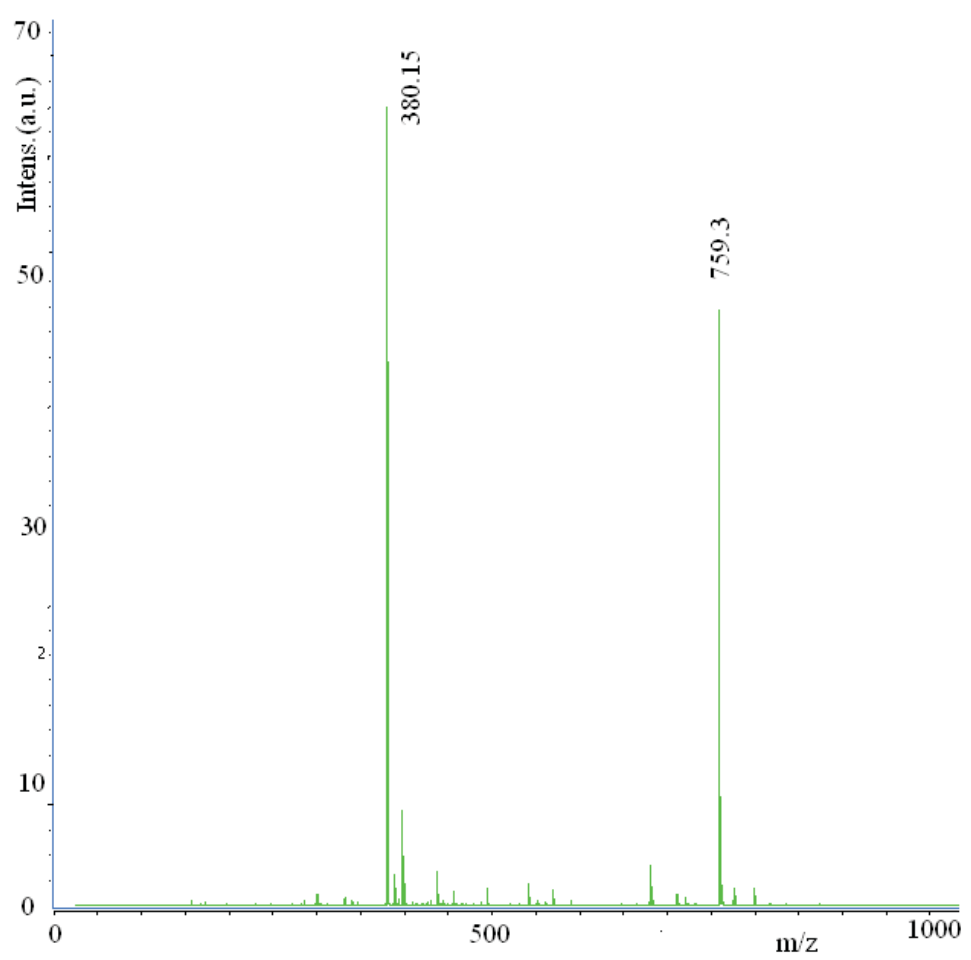

Figure 4. ESI-MS of product obtained from cyclocondensation reaction between $\underline{1}$ and $\underline{2}$.

The FTIR spectrum of $\underline{\mathbf{3}}$ does not show any absorption for aldehyde $\mathrm{C}=\mathrm{O}\left(1680 \mathrm{~cm}^{-1}\right)$ and amine $\mathrm{N}-\mathrm{H}(3390$ and $\left.3315 \mathrm{~cm}^{-1}\right)$ stretches, while absorption bands characteristic to the new groups $\mathrm{C}=\mathrm{N}\left(1634 \mathrm{~cm}^{-1}\right)$ and $\mathrm{C}=\mathrm{C}(1607$ and $\left.1507 \mathrm{~cm}^{-1}\right)$ are present. The absorption bands localized between 697 and $837 \mathrm{~cm}^{-1}(v \mathrm{C}-\mathrm{H}$ aromatic from benzene rings), $1268-1286 \mathrm{~cm}^{-1}$ (the stretching vibration of tertiary amine) and 2856-2930 (C-H aliphatic from cyclohexane) are present.

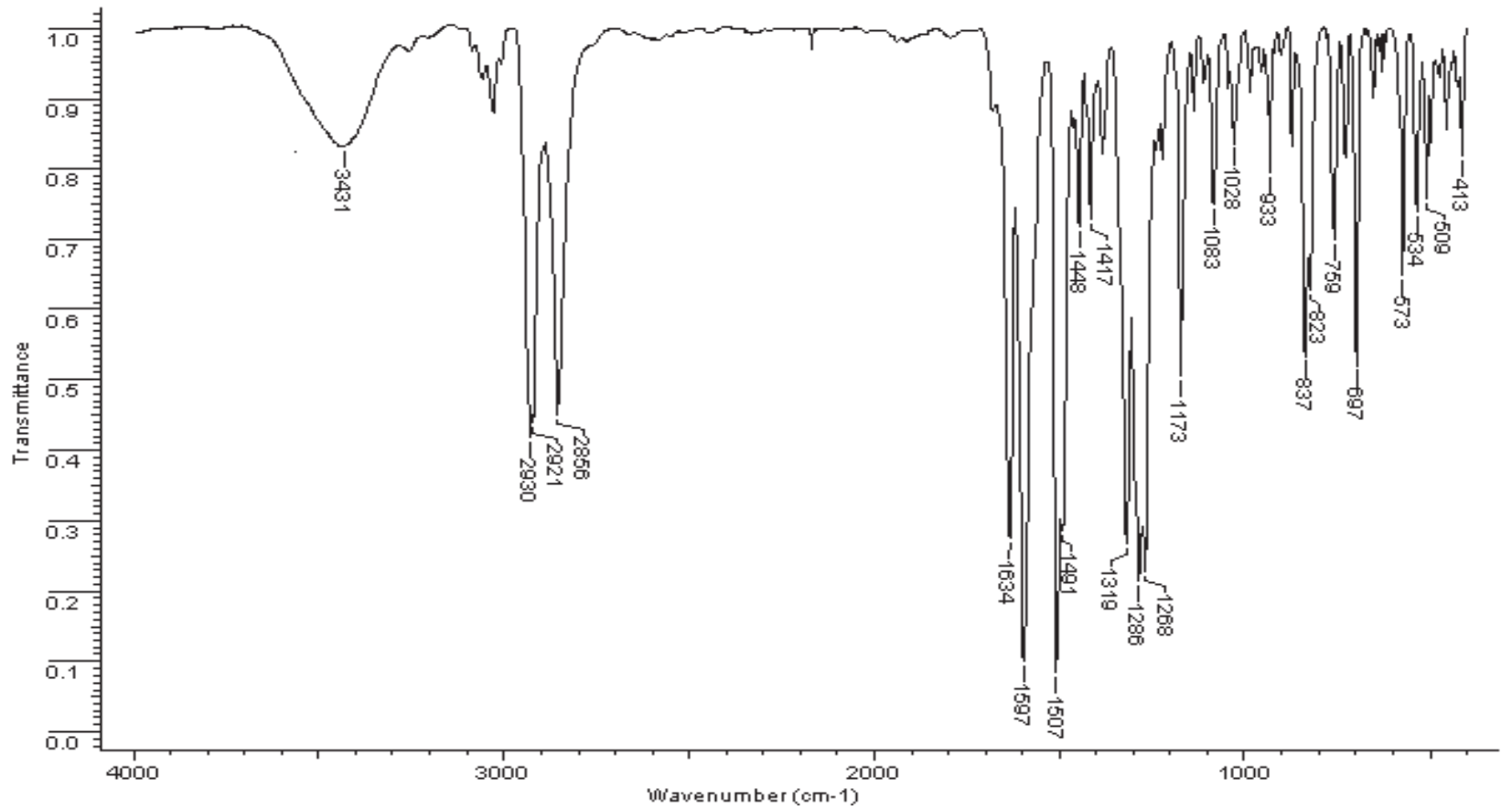

Figure 5. FTIR (KBr pellet) spectrum of $\underline{3}$.

When a chloroform solution of $\underline{\mathbf{3}}$ was treated with $\mathrm{SnCl}_{2} \cdot 2 \mathrm{H}_{2} \mathrm{O}$ in acetonitrile, the UV-vis spectrum showed a bathocromic shift (Figure 6). The macrocycle showed absorptions situated at 334 and $394 \mathrm{~nm}$. The addition of transitional 
metal salt to $\underline{\mathbf{3}}$ showed changes in the electronic spectrum, the peaks at 334 and $394 \mathrm{~nm}$ are slightly hypsochromically shifted and their intensity is diminished while a new absorption at $444 \mathrm{~nm}$ that increased with the quantity of the salt was observed. The cations were complexed by azomethine bonds leading to more planar structures.

The $\underline{3}$ has a high thermal thermostability due to the imine structure and absence of end groups, the onset degradation temperature was observed at $348{ }^{\circ} \mathrm{C}$ and thermal destruction took place in two steps $\left(340-448{ }^{\circ} \mathrm{C}\right.$ and weight loss $=$ $23.2 \%$ and $448-590{ }^{\circ} \mathrm{C}$, weight loss $=46.3 \%$ ). An endothermic peak observed at $340{ }^{\circ} \mathrm{C}$ was assigned to melting of $\underline{3}$. The DSC runs showed no transitions between $-40-300{ }^{\circ} \mathrm{C}$.

In summary, a Schiff base macrocycle with rhomboidal shape was synthesized by [2+2] cyclocondensation reaction of 4,4'-bisformyl triphenylamine with $(\mathrm{R}, \mathrm{R})$-1,2-diaminocyclohexane. ${ }^{1} \mathrm{H}-\mathrm{NMR}$ spectroscopy indicated that macrocycle adopt different conformations in solution as result of anti-syn isomerization process that takes place by a ring inversion induced by a concerted rotation around imine bonds. The macrocycle can bind cations and change its absorption spectrum.

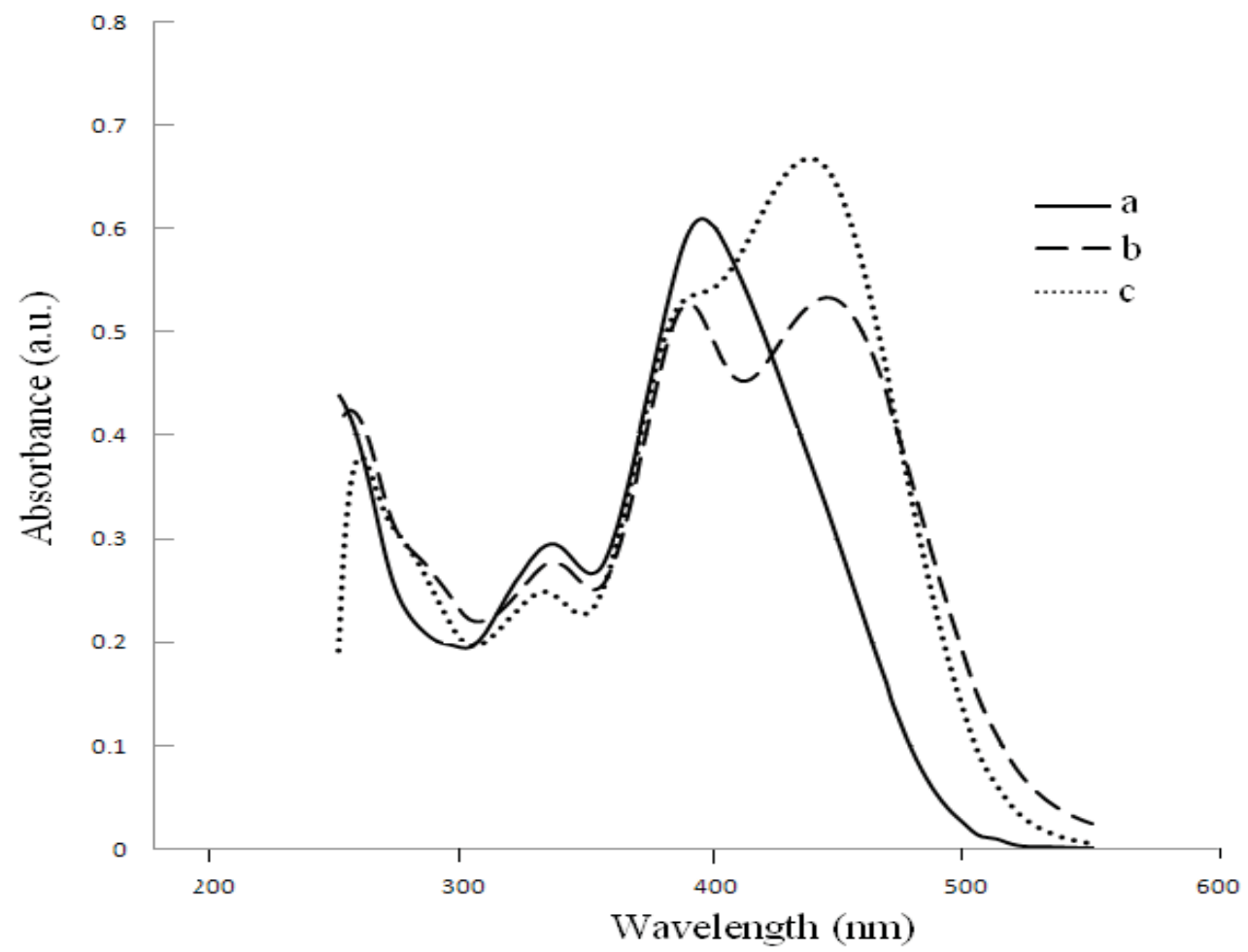

Figure 6: UV-vis spectra change of $\underline{3}$ during the addition of $\mathrm{SnCl}_{2}$ : (a) 0 , (b) $\underline{3} / \mathrm{SnCl}_{2}=1 / 1$ molar ratio and (c) $\underline{3} / \mathrm{SnCl}_{2}=1 / 2$ molar ratio. (solvent: dichloromethane/acetonitrile $=1 / 1$ ) $[\underline{3}]=1.10^{-5} \mathrm{M}$.

\section{Experimental}

Materials

Triphenylamine (Aldrich, 97\%) and (1R,2R)-trans-1,2-diaminocyclohexane (1) (Aldrich, 98\%) were used as received. Solvents were purchased from Aldrich source and were dried using the usual procedures. All manipulations of air/ moisture-sensitive materials were handled under nitrogen atmosphere. 4,4'-Diformyl triphenylamine (2) was synthesized by formylation of triphenylamine in presence of high excess of $\mathrm{POCl}_{3} / \mathrm{DMF}$ mixture.

\section{Rhombimine $\underline{3}$}

A solution of dialdehyde $\underline{\mathbf{2}}(0.4457 \mathrm{~g}, 1.48 \mathrm{mmol})$ in dichloromethane $(5 \mathrm{ml})$ was added to a solution of $(1 R, 2 R)$-trans1,2-diaminocyclohexane $\underline{\mathbf{1}}(0.1691 \mathrm{~g}, 1.48 \mathrm{mmol})$ in $15 \mathrm{ml}$ dried $\mathrm{CH}_{2} \mathrm{Cl}_{2}(20 \mathrm{~mL})$ at room temperature and stirred for 5 hours under gentle reflux. The solvent was evaporated and the residue was crystallized from N,N-dimethylformamide giving colorless fine powder of $\underline{\mathbf{3}}$ in $85.7 \%$ yield $(0.48 \mathrm{~g}) . \mathrm{Mp}=325^{\circ} \mathrm{C}$ (with decomposition).

\section{Instrumentations}

The FT-IR spectra were recorded in KBr pellets on a Bruker Vertex 70 spectrometer, while UV-Vis absorption spectra were obtained on a Specord 200 Analytik Jena spectrophotometer using $10 \mathrm{~mm}$ quartz cells. ${ }^{1} \mathrm{H}-\mathrm{NMR}$ spectra were 
recorded at room temperature on a Bruker Avance DRX-400 spectrometer $(400 \mathrm{MHz})$ as solutions in $\mathrm{CDCl}_{3}$ and chemical shifts are reported in ppm and referenced to TMS as internal standard. ESI-MS analysis was performed using an AG-QTOF instrument and methanol/chloroform as solvent. Thermal gravimetric analysis (TGA) was performed by means of a Mettler Toledo TGA-SDTA 851e device, in $\mathrm{N}_{2}$ atmosphere, with a flow of $20 \mathrm{ml} / \mathrm{min}$, and a heating speed of $10 \mathrm{~K} / \mathrm{min}\left(25-850^{\circ} \mathrm{C}\right.$ range $)$. DSC measurements were performed with a Mettler DSC-12E apparatus, in nitrogen.

\section{Acknowledgments}

The authors (MG and LS) thank the Romanian National Authority for Scientific Research for financial support (Grant PN II-IDEI-963).

\section{References}

[1]. For relevant reviews on imine macrocycles, see: (a) Borisova, N. E.; Reshetova, M. D.; Ustynyuk, Y. A. Chem. Rev. 2007, 107, 46-79. (b) MacLachlan, M. J. Pure Appl. Chem. 2006, 78, 873-878.

For synthesis of imine macrocyles based on(R,R)-1,2-diaminocyclohexane, see:

[2]. (a) Gawronski, J.; Kolbo, H.; Kwit, M.; Katrusiak, A. J. Org. Chem. 2000, 65, 5768-5773. (b) Kwit, M.; Gawronski, J. Tetrahedron: Asymmetry 2003, 14, 1303-1308 (c) Gawronski, J.; Brzostowska, M.; Kwit, M.; Plutecka, A.; Rychlewska, U. J. Org. Chem. 2005, 70, 10147-10150. (d) Kwit, M.; Skowronek, P.; Kolbon, H.; Gawronski, J. Chirality 2005, 17, 93-100. (e) Gawronski, J.; Gawronska, K.; Grajewski, J.; Kwit, M.; Plutecka, A.; Rychlewska, U. Chem. Eur. J. 2006, 12, 1807-1817. (f) Kwik, M; Gawronski, M. Org. Lett. 2006, 8, 2921 2924 (g) Gawronski, J.; Kwit, M.; Grajewski J.; Gajewy J.; Dlugokinska A. Tetrahedron: Asymmetry 2007, 18, 2632-2637. (h) Skowronek, P.; Gawronski,J. Org. Lett. 2008, 10, 4755-4758.

[3]. (a) Chadim, M.; Budesinsky, M.; Hodacova, J.; Zavada, J.; Junk, P. C. Tetrahedron: Asymmetry 2001, 12, 127133. (b) Hodackova, J.; Budesinsky, M. Org. Lett. 2007, 9, 5641-5643.

[4]. (a) Kuhnert, N.; Lopez-Periago, A. M. Tetrahedron Lett., 2002, 43, 3329-3332. (b) Kuhnert, N.; Strassnig, C.; Lopez-Periago, A. M. Tetrahedron: Asymmetry 2002, 13, 123-128. (c) Kuhnert, N.; Rossignolo, G. M.; LopezPeriago, A. Org. Biomol. Chem. 2003, 1, 1157-1170. (d) Kuhnert, N.; Burzlaff, N.; Patel, C.; Lopez-Periago, A. Org. Biomol. Chem.2005, 3, 1911-1921 (e) Kuhnert, N.; Lopez-Periago A.; Rossignolo, G. M. Org. Biomol. Chem., 2005, 3, 524-537. (f) Kuhnert N.; Patel , C.; Jami, F. Tetrahedron Lett. 2005, 46, 7575-7579.

[5]. (a) Gao, J.; Martell, A. E. Org. Biomol. Chem.2003,1, 2795-2800; (b) Gao, J.; Martell, A. E. Org. Biomol. Chem.2003,1 2801-2806. (c) Gao, J.; Reibenspies, J. H.; Zingaro, R. A.; Wooley, F. R.; Martell, A. E.; Clearfield, A. Inorg. Chem. 2005, 44, 232-241.

[6]. Srimurugan, S.; Viswanathan, B.; Varadarajan, T. K.; Varghese, B. Org. Biomol. Chem. 2006, 4, 3044-3047.

[7]. Kraft, A.; Grimsdale, A.C.; Holmes,A. B. Angew. Chem. Int. Ed. 1998, 37, 402-428.

[8]. Mitchke, U.; Bäuerle, P. J. Mater. Chem. 2000, 10, 1471-1507.

[9]. Friend, R. H.; Gymer, R. W.; Holmes, A. B.; Burroughes, J. H.; Markes, R. N.; Taliani, C.; Branley, D. D. C.; Santos, D. A. D.; Brédas, J. L.; Lőgdlund, M.; Salaneck, W. P. Nature 1999, 397 121-128.

[10]. Law, K. Y. Chem. Rev., 1993, 93, 449-486.

[11]. Forrest, S. R. Chem. Rev., 1997, 97, 1793-1896.

[12]. Walzer, K.; Maening, B.; Pfeifer, M.; Leo, K. Chem. Rev. 2007, 107, 1233-1271.

[13]. Lambert, C.; Gaschler, W.; Schmalzlin, E.; Meerholz, K.; Brauchle, C. J. Chem. Soc., Perkin Trans. II 1999, 577-588.

[14]. Song, Y.; Di, C.; Yang, X.; Li, S.; Xu, W.; Liu, Y.; Yang, L.; Shuai, Z.; Shang D.; Zhu D. J. Amer. Chem. Soc. 2006, 128, 15940-15941.

[15]. Grigoras, M.; Antonoaia, N. C. Eur. Polym. J. 2005, 41, 1079-1089.

[16]. Grigoras, M.; Stafie, L.; Totolin, M. Rev. Roum. Chim. 2008, 53, 787-794.

[17]. M. Grigoras, L. Stafie, Des. Mon. Polym. 2009, 12, 177-196. 